International Journal of Agriculture, Environment and Bioresearch

Vol. 4, No. 03; 2019

ISSN: $2456-8643$

\title{
EFFORTS TO REDUCE GREENHOUSE GASES, AIR POLLUTION AND CLIMATECHANGE: GLOBAL AND REGIONAL PERSPECTIVES.
}

\author{
Asawa Priya,Varshney Naincy ,Pandey Vivek,Kashyap Isha, Singh Shraddha,Gupta Saumya and Singh \\ Manali \\ Department Of Biotechnology Invertis University Bareilly
}

http://doi.org/10.35410/IJAEB.2019.129144

\begin{abstract}
It was recognized before 30years ago that the increase in tropospheric ozone from air pollution is an important green house terms. Later on chemistry and climate linked strongly when chlorofluorocarbons (CFCs) are recognized on stratospheric ozone. Fossil fuel combustion for power generation, burning of forest, transportation, cooking with solid fuels are the major sources of air pollution which are continuously increasing. The emission of colourless gas carbon di oxide are the ultimate by-product of all forms of burning. The greenhouse effect was largely a problem of solving the physics and thermodynamics and dynamics of climate as $\mathrm{CO} 2$ does not react with other gases. Again the chemistry strongly linked with the climate when there was a independent discovery on CFC on stratospheric ozone and on the greenhouse effect. The solar effect was dominating the reduced greenhouse effect on ozone and the reduced long wave radiation of the cooler stratosphere and because of this the air chemistry and climate was strongly linked. The main and most important thing to note is that 2.4 degree calcius warming is the equilibrium warming. The masking effects of aerosols is considered to set the stage. The origin of air pollution refer as aerosol as atmoshpheric brown clouds. It is nearly impossible to interpret or understand the factors for global climate change during th last century without the proper treatment of $\mathrm{ABCs}$ in climate model. For solving the air pollution problem and global warming the living condition of the rural poor has to be improve and the negative health impact of smoke need to be minimize. We can reduce air pollution by replacing solid fluid for cooking with other clean energy sources just like biogas plants solar energy etc are the promising efforts to overcome the problem of air pollution .
\end{abstract}

Keywords: greenhouse gases, CFC, aerosols, global warming

\section{INTRODUCTION}

The Residence time and physical and chemical properties of a number of important air pollutants and greenhouse gases and particles are of particular importance in environmental risk assessment [1].The Main compounds of significance in the present context and their role in promoting toxic and changes in climate conditions[2] 
International Journal of Agriculture, Environment and Bioresearch

Vol. 4, No. 03; 2019

ISSN: $2456-8643$

\begin{tabular}{|c|c|c|c|}
\hline Compound & Residence time & Toxic properties & $\begin{array}{l}\text { Climate change } \\
\text { properties }\end{array}$ \\
\hline Carbon dioxide & 150 years & $\begin{array}{l}\text { Acidification } \\
\text { sea waters, affect } \\
\text { photosynthesis }\end{array}$ & $\begin{array}{l}\text { Climate } \\
\text { gas, long } \\
\text { residence time }\end{array}$ \\
\hline Nitrous oxide & 110 years & $\begin{array}{l}\text { Destruction } \\
\text { the stratospheric } \\
\text { ozone layer }\end{array}$ & $\begin{array}{l}\text { Climate } \\
\text { gas, long residence } \\
\text { time }\end{array}$ \\
\hline Methane & 10 years & Precursor & Climate \\
\hline Compound & Residence time & Toxic properties & $\begin{array}{l}\text { Climate change } \\
\text { properties }\end{array}$ \\
\hline Carbon dioxide & 150 years & $\begin{array}{l}\text { Acidification } \\
\text { sea waters, affect } \\
\text { photosynthesis }\end{array}$ & $\begin{array}{l}\text { Climate gas, long } \\
\text { residence time }\end{array}$ \\
\hline Nitrous oxide & 110 years & $\begin{array}{l}\text { Destruction of } \\
\text { the } \\
\text { tospheric ozone layer }\end{array}$ & $\begin{array}{l}\text { Climate } \\
\text { gas, long residence } \\
\text { time }\end{array}$ \\
\hline Methane & 10 years & Precursor of & Climate \\
\hline
\end{tabular}

substantially in Europe and North America due to national and international action [ 3] This has been Particularly the case for sulphur .substantial emission reductions for particles, nitrogen oxides and volatile organic compounds have also been achieved shown in above table. Air pollution and climate change issues converge in the increasing background concentration of ozone .The increasing level of ozone results in the reduce plant growth and has adverse effect on the health of human[4]. A higher background level means that less local regional pollution is required to exceed air quality standards. The increased background has resulted in ozone being rated as third most significant greenhouse gases after $\mathrm{CO} 2$ and methane by the IPCC(Intergovernmental panel on climate change)[5] .Many problems faces with particles are arise atmospheric particles have received increasing attention on both because of their tedious role as air pollutants and as an atmospheric aerosols that affect the radiation balance of the atmosphere [6]

\section{Climate change-on the threshold of large- scale action}

For a long period in the establishment of far reaching control of atmospheric pollutants no or little attention was paid to green house gases and climate change. Emission of green house gas (GHGs) continued to increase [3].Some of the earlier air pollution have been made for climate 
change this is the specially the case of control of ozone depleting substances such as CFCs(chlorofluorocarbon) known as freons. It is very powerful greenhouse gas which deplete the stratospheric ozone layer [7] According to the Montreal protocol it was detected that the stratospheric ozone was destructed at Antarctica promoted the control of ozone depleted substances [8].From the control of these substances the climate change policies have been benefited considerably over the past 20 years .

In addition to ODS(ozone depleted substances) HFCs (hydroflourocarbon),PFCs(perflorinated compound) are some halo carbons which are partially used to replace substances these are not very significant green house gases [9]

Global warming and climate changes may harm maine peoples, wildlife and also environment[10]. Global warming is caused by a blanket of pollution that traps heat around the earth. This pollution comes from cars, factories, homes, and power plant that burns fossil fuels such as oil, coal, natural gas, and gasoline. Global warming known to no boundaries. It enters the atmosphere spreads across the globe and traps heat around the earth for 50-200years after it is emitted .That is why we need to reduce global warming pollution now ,because of our children ,we still feel the effect of global warming for years to come. Currently, the level of carbon dioxide in the atmosphere are at their highest levels in hundreds of thousands of year [11

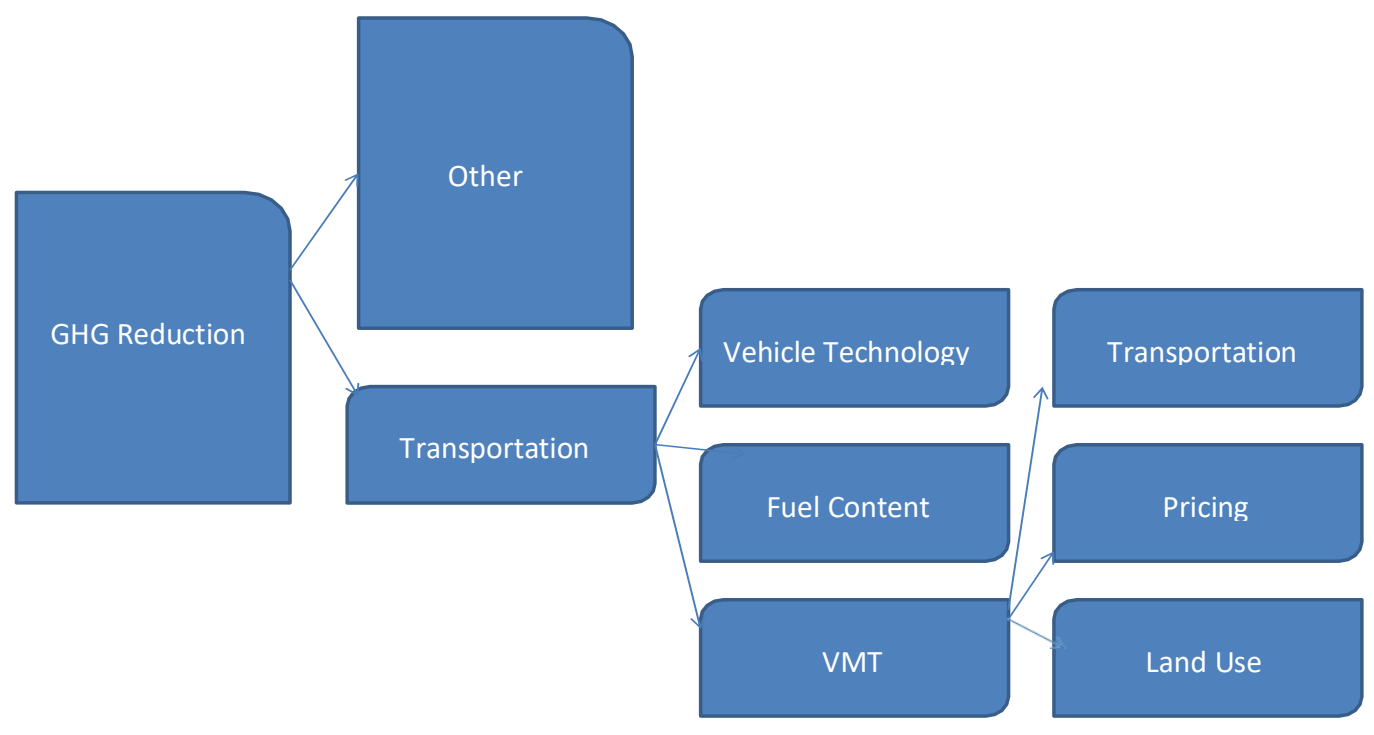


According to the highest rate of childhood asthma in the nation, rising seas and severe storms battering are coastal homes and towns[12] This global warming makes the oceans more acidic which harms the fisheries by which bad air days and many disease like tick-borne threads to winter tourism industries and to our foll foliage [ 13].The above are the reasons for many health change as well as environmental change and many economic problems are causing in the maine .The burning of fossil fuels are the big reasons which contributes to the air pollution such as sulphur dioxide nitrogen oxide mercury and other air toxic which combinly creates other problems also like unhelthful smog and soot mercury contamination of maine people waters and wildlife and acid rain and ocean acidification [ 14] Roughly $75 \%$ to $85 \%$ of the fossil fuels consumed by maine more than 1.5 billion gallons every year this is the data of burned fuels which is directly burned from our buildings and vehicles by various means[ 15] ".The other remaining is used for us to generate electricity at power plants in maine and across state borders. About $9 \%$ of the power comes from coal plants and both coal mining and pollution from those power plants takes a heavy toll. Burning fossil fuels such as natural gas, coal, oil and gasoline raises the level of carbon dioxide in the atmosphere, and carbon dioxide in the atmoshphere and carbondioxide is a major contributer to the global warming as well as greenhouse effect .The demand of fossil fuel must be reduced to reduce global warming by using energy more wisely .

Global warming- global warming is the term which indicate the increase in the average temperature of the atmosphere[16] .The increased volumes of carbon dioxide and other green house gases released by the burning of fossil fuels and other human activities, contribute to the warming of the earth. The amount of heat trapped in the atmosphere depends mostly on the concentration of green house gases [17].

Their contribution to global warming- the greenhouse gases which cause greenhouse warming of global climate ( excluding water vapour)are carbon dioxide, methane and number of other trace gases like nitrous oxide (N2O), tropospheric ozone, chlorofluorocarbon (CFCs), hydro chloro fluoro carbon (HCFCs), methyl chloroform (CH3CCL3), carbon tetrachloride (CC14), sulphur dioxide, fluorine, bromine, iodine, and compounds of nitrogen and sulphur[6]

The major green house gases are carbon dioxide, ozone, methane, chlorofluorocarbon and water vapours [18] Due to anthropogenic activities, there is increase in the concentration of the green house gases in the air, which result in the increase in average surface temperature. Come on roads and trees are cut to make way for new homes. All of them have direct or indirect effect on global warming [19]

There may be more warming up in higher latitudes late autumn and winter, than in tropics. And flooding of many coastal areas (land and islands) due to rising sea levels resulting from the thermal expansion of the oceans, the melting of glaciers and ice sheet, and probably, from the melting of polar ice caps [20] An increase in global average temperature is predicted to increase the amount of water vapour in the atmosphere thereby increasing the long wave optical depth, trapping more long- wave radiation and increasing the temperature further. Increase in global average temperature will lead to dislocation of suitable land for agriculture, and thus may adversely affect the world food production 
[21] The dislocation and possible extinction of certain biological species and ecosystems cannot be ruled out[22] . And increase it the severity of storms. Other effects include more evaporation transpiration in tropics, alteration in existing precipitation patterns, effect on hydrological cycle, effect on human health (like heat strokes), etc.Remedial measures- since, $\mathrm{CO} 2$ accounts for about half of the greenhouse gases and there is a strong evidence linking temperature and $\mathrm{CO} 2$ changes, therefore, the best way to solve this problem of global warming due to increasing concentration of $\mathrm{CO} 2$ is to use sources of energy that do not produce carbon dioxide such as wind, hydroelectric, geothermal, solar, tidal and nuclear energy. Similarly effect. , the emission of other greenhouse gases in the atmosphere should also be stopped to prevent the enhance greenhouse[23].

Effect on global warming- the emission of green house gases particularly $\mathrm{CO} 2$ is leading to global warming.

Ozone layer- ozone layer depletion ozone layer is the this shield high up in the sky that stops ultra violet rays from reaching the earth. As a result of human activities, chemicals, such as chloroflurocarbon (CFCs) were released into the atmosphere which contributed to the depletion of ozone layer [24]

The Green House Effect : The CO2 Blanket- On a cold winter night,a blanket keeps the body warm not because the blanket gives off any energy. Rather the blanket traps the body heat preventing it from escaping to the colder surroundings. Similarly the $\mathrm{CO} 2$ blanket traps the long wave radiation given off by the planet [25] The trapping of the long wave radiation is dictated by quantum mechanics. The two oxygen atoms in $\mathrm{CO} 2$ vibrate with the carbon atom in the centre and the frequency of this vibration coincide with some of the infrared wavelength of the long wave radiation. When the frequency of the radiation from the Earth's surface and the atmosphere coincides with the frequency of $\mathrm{CO} 2$ vibration, the radiation is absorbed by $\mathrm{CO} 2$, and converted to heat by collision with other air molecules, and then given back to the surface

[26] As a result of this trapping, the outgoing long wave radiation is reduced by increasing $\mathrm{CO}$. Not as much heat is escaping to balance the net incoming solar radiation. There is excess heat energy in the planet, i.e., the system is out of energy balance. As $\mathrm{CO} 2$ is increasing with time, the infrared blanket is becoming thicker, and the planet is accumulating this excess energy. [27]

\section{Global warming: getting rid of the excess energy.}

We know from basic infrared laws of physics, the so-called Planck's black body radiation law, that warmer bodies emit more radiation[28]. So the planetary system will get rid of this excess energy by warming and thus emitting more infrared radiation, until the excess energy trapped is given off to space and the surface-atmosphere system is in balance[29]. That, in a nutshell, is the theory of the greenhouse effect and global warming. A rigorous mathematical modeling of this energy balance paradigm was originated by Arrhenius (1896), but the proper accounting of the energy balance of the coupled surface-atmosphere system had to await the work of Manabe and Wetherald in 1967 (Manabe and Wetherald, 1967).CFCs: the super greenhouse gas for nearly eighty years since the Arrhenius paper, climatescientists assumed that $\mathrm{CO} 2$ was the main anthropogenic or manmade greenhouse gas (e.g., SMIC Report, 1971). Since CO2 does not react 
with other gases in the atmosphere, the greenhouse effect was largely a problem of solving the physics, thermodynamics and aerodynamics of climate. This picture changed drastically when it was discovered that there are other man- made gases, which on a per molecule basis could be up to ten thousand times stronger than theCO2 greenhouse effect (Ramanathan,1975)[8] . Chlorofluorocarbons, or CFCs, used as refrigerants and propellants in deodorizers, drug delivery pumps, etc are some of the strongest of such super greenhouse gases. These are purely synthetic gases. In 1974, Molina and Rowland published a famous paper in Nature (Molina and

Rowland, 1974)[30].They proposed that CFC11 and CFC12 (known then as Freon 11 and Freon 12) will build up in the atmosphere include ing the stratosphere, because of their century or longer life time.

According to their theory, UV radiation from the sun will photo dissociate the CFCs, and the released chlorine atoms will catalytically destroy ozone in the stratosphere.

Challenges With implementation of climate change Reduction Strategies Economic Growth/Vested Interests, and Climate Change Deniers[31][32].

As the issue of global warming became more publically known through the 90s with the advantage global negotiations like Kyoto,[33][34]there was a rise in skepticism over the science of climate change .There was backlash from the fossil fuel industry, individual who felt their freedoms were threatened ,those who thought global warming was a conspiracy

,and lobbyists with various political agendas[35].Wealthy corporations spent millions on advertising against the validity of climate change, challenged the quality of scientific work from the IPCC, and critized and emphasized the scientific uncertainities associated with the work. Also, the media coverage of loud skeptics worked to undermine the validity and to suppress the voice of the scientific community (Weart,2012)(Incropera,2016).

The fossil fuel is a multi- trillion doller industry, and for this reason is a significant part of many developed countries a economy (Incropera,2016)[36] .As mentioned before, Canada found itself at odds with meeting its KP targets and its desire to exploit oil from the tar sands

.A lot of nation conflicted, and will not significantly reduce emissions if it means a cut to their economy .So ,there is an undeniable struggle between economic growth and environmental impact that has to be grappled with .Indeed, this was also a major concern for countries like India and china that reaped economic benefit from and development from their increased use of fossil fuels.

\section{Regional plumes of widespread brown clouds}

Brown clouds are usually associated with the brownish urban haze such seen over the horizon in most urban skies. The brownish color is due to strong solar absorption by black carbon in the soot and NO2. Due to fast atmospheric transport, the urban and rural haze becomes widespread trans-oceanic and trans-continental plumes of ABCs in a few days to a week. Until 2000 we had to rely largely on global models to characterize their large-scale structure. The launch of TERRA satellite with the MODIS instrument provided a whole new perspective of the $\mathrm{ABC}$ issue, 
because MODIS was able to retrieve aerosol optical depths (AODs) and effective particle size over the land as well as the oceans (Kaufman et al., 2002). Furthermore, NASA's ground based AERONET (Aerosol Robotic Network) sites with solar-disc scanning spectroradiometers provided not only ground truth over 100 locations around the world but also aerosol absorption optical depth and single scattering albedo (Holben et al., 2001). Field observations such as the Indian Ocean Experiment (Ramanathan et al., 2001a) and ACE-Asia (Huebert et al., 2003) provided in situ data for the chemical composition of $\mathrm{ABCs}$ as well as their vertical distribution. Another important development is the advent of atmospheric observations with light-weight and autonomous UAVs (unmanned aerial vehicles), which could be flown in stacked formation to measure directly solar heating rates due to ABCs (Ramanathan et al., 2007a; Ramana et al., 2007). By integrating these data and assimilating them in a global framework, Chung et al. (2005) and Ramanathan et al. (2007b) were able to provide a global distribution of aerosol optical properties dimming and atmospheric solar heating for the 2000-2003 time period[37] .Using these integrated data sets, we characterize the various $\mathrm{ABC}$ plumes around the world [38] . The figure shows anthropogenic AODs for all four seasons of the year. The following major plumes are identified in Fig. 5: 1) Dec to March: Indo-

Asian-Pacific Plume; N Atlantic-African-S Indian Ocean Plume; 2) April to June: N AtlanticAfrican-S Indian Ocean Plume; E Asian- Pacific-N American Plume; Latin American Plume; 3) July to August: N American Plume; European Plume; SE AsianAustralian Plume; N AtlanticAfrican-S Indian Ocean Plume; Amazonian Plume; 4) September to November: E Asian-PacificN American Plume; Latin American Plume[39]. It should be noted that ABCs occur through out the year in most continental and adjacent oceanic regions, but their concentrations peak in some seasons: dry season in the tropics and summer seasons in the extra tropics. Simulated AODs for year 2001 using a chemical transport model (the LLNL/IMPACT model at Univ. of Michigan) documented elsewhere (Liu and Penner, 2002; Rotman et al., 2004; Liu et al., 2005; Feng and Penner, 2007) (Feng and Ramanathan, in preparation)[40]. There is overall correspondence between regional plumes derived from observationally retrieved AODs and simulated AODs. The simulations also reveal the seasonally dependent plumes identified from the assimilated values; since the color scales and seasons are identical in the two figures, it can be seen that the simulate values are also quantitatively consistent.

\section{Global distribution of dimming}

The major source of dimming is $\mathrm{ABC}$ absorption of direct solar radiation. This is further enhanced by the reflection of solar radiation back to space by $\mathrm{ABCs}(41)$. This should be contrasted with the TOA forcing that is solely due to the reflection of solar radiation back to space. This distinction has been ignored frequently; result, the dimming has been mistakenly linked with surface cooling trends (e.g., Wild et al., 2004; Streets et al., 2006)[42] The problems with this approach are the following: for black carbon, the dimming at the surface is accompanied by positive forcing at the top of the atmosphere (Ramanathan and Carmichael, as a 2008), thus it is erroneous to assume dimming will result in cooling[43]. Furthermore, as we will show later, the surface dimming due to $\mathrm{ABCs}$ with absorbing aerosols is a factor of 2-5 larger than the aerosol TOA forcing, and for many regions they can be even of opposite sign[44]. Most of the solar absorption is due to elemental carbon and some organics, and these aerosol species 
are referred to as black carbon. The reflection of solar radiation is due to sulfate, nitrate, organic matter, fly ash and dust. Additional dimming is caused by soluble aerosols (e.g. sulfate) nucleating more cloud droplets, which in turn enhance reflection of solar radiation back to space[44]. But the major source of dimming is due to the direct absorption and reflection of solar radiation by aerosols along with emissions of black carbon and sulfur (gaseous precursor of sulfate). Over most regions of the $\mathrm{ABC}$ plumes, the dimming is large in the range of 6-25 $\mathrm{W} / \mathrm{m} 2$. In remote oceanic regions, the dimming is much smaller and is in the range of $1-3 \mathrm{~W} / \mathrm{m} 2$. The large dimming values over oceanic regions downwind of polluted continents are consistent with the results from the Indian Ocean Experiment (Ramanathan et al., 2001) [45]. Global averages $\mathrm{ABC}$ forcing at the surface, in the atmosphere, and at the top of the atmosphere is compared with the greenhouse forcing. At the TOA, the $\mathrm{ABC}$ (that is, $\mathrm{BC} \mathrm{p}$ non-BC) forcing of $1.4 \mathrm{~W} / \mathrm{m} 2$, which includes a $1 \mathrm{~W} / \mathrm{m} 2$ indirect forcing, may have masked as much as $50 \% 25 \%$ ) of the global forcing due to GHGs. The estimated aerosol forcing of $1.4 \mathrm{~W} / \mathrm{m} 2$ due to $\mathrm{ABCs}$ is within 15\% of the aerosol forcing derived in the recent IPCC report (IPCC, 2007) [46]. The main point to note is that, because of the solar absorption within the atmosphere $(3 \mathrm{~W} / \mathrm{m} 2)$, the $\mathrm{ABC}$ surface forcing $(4.4 \mathrm{~W} / \mathrm{m} 2)$ is a factor of 3 larger than the TOA forcing $(1.4 \mathrm{~W} / \mathrm{m} 2)$. The dimming at the surface is approximately estimated as surface forcing/ (1As), w here As is surface albino. Assuming an average As of 0.15 , we obtain for the dimming $5.2 \mathrm{~W} / \mathrm{m} 2(1 / 44.4 \mathrm{~W} / \mathrm{m} 2$ 10.85). This is the dimming that occurred during 2000-2002 due to anthropogenic aerosols, or, ABCs. Since emissions of some aerosol precursors such as SO2 peaked in the 1970s followed by a decline of about $30 \%$ from the 1970s to date, the dimming during the 1970s could have been larger [47]. There is an important distinction between the dimming by scattering aerosols like sulfate, and that due to absorbing aerosols like soot [48] . For sulfate, the dimming at the surface is nearly the same as the net radioactive forcing due to aerosol, since there is no compensatory heating of atmosphere; therefore, a direct comparison of the surface dimming with GHGs forcing is appropriate. For soot, however, the dimming at the surface is mostly by the increase in atmospheric solar absorption, and hence the dimming does not necessarily reflect a cooling effect. It should also be noted that the dimming at the surface due to soot solar absorption can be a factor of 3 larger than the dimming due to reflection of solar (a cooling effect).

How long has the dimming been going on IPCC (2007)[46] [49] estimates that the net global average aerosol forcing from pre-industrial to year 2005 is negative. This negative forcing is due to enhanced reflection of solar radiation [50]. The deduction from this finding is that global scale dimming has been going on since the pre-industrial to now. The magnitude of the aerosol forcing from IPCC (2007) is $1.2 \mathrm{~W} / \mathrm{m} 2$ [46,49,50]. In terms of trend, assuming that most of the aerosol forcing is from 1900 onwards, the trend is of the order of 0.1 (with an uncertainty of factor of

2) $\mathrm{Wm} 2$ per decade. However, the forcing at the surface $(4.4 \mathrm{~W} / \mathrm{m} 2)$ is much larger in magnitude than the TOA forcing. The global dimming trend due to ABCs is most likely of the order of $0.5 \mathrm{~W} / \mathrm{m} 2$ per decade (with an uncertainty of factor of two). It should also be noted that the dimming would have been larger in the 1970s[51] when the SO2 emission peaked (Streets et al., 2006)[52]. There have been numerous studies that claimed widespread reduction of solar radiation at the surface (Gilgen et al., 1998; Ohmura et al., 1989; Stanhill and Cohen, 2001; Lie pert, 2002) [53], using surface network of radiometers (mainly broad band pyranometers). We begin with the first study that used the term _ global dimming " (Stanhill and Cohen, 2001)[54]. 
They reviewed earlier studies and subselected the data to include only thermopile radiometers, and their data set included more than 150 stations from both the northern and southern hemisphere. The data covered the period from 1958 to 1992. Based on analysis of this data set, they reported a globally averaged dimming of $20 \mathrm{Wm} 2$ for a 34-year period from 1958 to 1992. This was followed by Liepert (2002), who conducted a trend analysis of the so- called GEBA network of pyranometers (over 150 stations) maintained by Ohmura et al. (1989) for the 19611990 period(55). Liepert differenced the decadal-average surface solar radiation between 19811990 and 1961-1970 and obtained a _elobally averaged" dimming of $7 \mathrm{~W} / \mathrm{m} 2$. Although Liepert refers to the inferred trend as a thirty year trend form 1961 to 1990 , it is really a twenty year trend since the difference is between two ten year periods (1961-1970 and 1981-1990) separated by 20 years. These trends are for downward solar radiation whereas we need the trend in absorbed solar radiation, which is obtained by multiplying the downward solar radiation trend by 0.85 (following Wild et al., 2004)(56). Thus the 20-year trend (1965-1985) in absorbed solar radiation is $6 \mathrm{Wm} 2$ for Liepert (2002), while the 34-year trend (1958-1992) in absorbed solar radiation at the surface is $17 \mathrm{Wm} 2$ for Stanhill and Cohen (2001)(57). The underlying message is that the dimming trend has been going on at least from the 1950s onwards. By analyzing later GEBA data sets, Wild et al. (2005) conclude that the dimming trend is reversing in most locations of the globe, except over S Asia(58). They suggest that this reversal to brightening commenced around 1990. Most of the GEBA stations analyzed in their data sets did reveal brightening.

However, the length of the period analyzed in their study is only of 6 years to about 10 years.

Prediction and detection: the missing warming As the importance of the greenhouse effect of trace gasses emerged, it became clear that the climatic problems were more imminent than earlier. It was though predicted by Madden and Ramanathan that the warmth would be seen by the year 2000[59]. The IPCC report confirmed this prediction, but the observed warming trend of any 0.8 dc from 1990 to 2005 , was the factor of two to three smaller than the magnitude predicted by most models as shown below[60].

\section{Magnitude of the predicted warming}

IPCC (2007) concludes that the climate system will warm by $3 \mathrm{dc}$ for doubling of co2. The radiative forcing for a doubling of $\mathrm{co} 2$ is $3.8 \mathrm{Wm} 2$. Thus, we infer that the climate sensitivity term is $1.25 \mathrm{Wm}-2 \mathrm{dc}$. If the planet including the atmosphere were to warm equally with no change in its composition including clouds, water vapours and snow covers[61]. Basically the atmosphere warms, the saturation vapour pressure increases exponentially (by about $75 \% \mathrm{dc}$ increase in L) sand as a result humidity increases.

The following is a list of ten steps that we can take to reduce greenhouse gas emission

Reduce ,Reuse, Recycle-we can do this by using minimal packaging products which reduce waste another option is we can go for recycling half of our household waste which can save 2400 pounds of carbondioxide annually . 
Use less heat and air conditioning-Adding insulation to the walls and installing wheather stripping or caulking around windows and doors can lower the cost of heating more the $25 \%$, which we are using to heat and cool our homes which ultimately reduce the amount of energy used. We can maintain the temperature at moderate level all times by switching off the lights while we are sleeping at nights or away during the day .Install a programmable thermostate because setting it just 2 degree lower in winter and higher in summer could safe about 20000 pounds of carbondioxide each year .

Replace your light bulb-Wherever possible practically arrange compact florescent light bulb in place of regular light bulbs it ultimately saves $\$ 30$ over the life of the bulb the advantage of using CFL are it last ten times longer then incandescent bulbs and it uses $2 / 3$ of less energy in comparision to normal bulbs. It also give of $70 \%$ less heat .If every canadian family replace a single regular bulb with the CFL it would eliminate 90billion pounds of green house gases .Another is same if we taking 7.5 million cars on the road which also eliminate 90 billion pounds of green house gases .

Drive less and Drive smart-Less driving means fewer emission besides saving gasoline walking and bikeing are creates forms of some exercise when you are driving you need to make sure that your car is running efficiently for example keeping your tires properly inflated can improve your gas milage by more then $3 \%$.If we are doing this we not only save our money but also it keeps 20 pounds of $\operatorname{co} 2$ out of atmoshphere .

Buy Energy - Effecient products -Now a days because of increasing technology very efficient models are available in the market just like CFLs are designed which uses far less energy than the normal bulbs by providing more natural looking white light.

Use Less Hot Water-We can do this by setting the temperature of our heaters at 120 degrees to save energy and if the heater is 15 years old than wrap in a insulating blanket. You can buy the low flow showerheads which ultimately save hot water and it almost saves about 350pounds of carbon di oxide yearly. There are many other ways also to reduce the use of hot water like you can use warm or cold water to wash your clothes in pace of warm and cold water. These above ways of preventions can save alone about 500pounds of carbondioxide yearly from a single households.

Use The -offl Switch- Save electricity and save light is benefitted for us as well as for the sustainable development. We can go for it by using the required amount of light and by switching off the unwanted light while you are leaving the room. We can not only focus on the light we shall be also go for the other electric appliance which required energy just like television, refrigerator, computer which you are not using. Not only electricity you should also need to use the water in required amount like turn off the tap while brushing, shampooing, washing the car until we are not required for rinsing.

Plant A Tree- This is the best way to reduce green house gases.Because we just wanted that the amount of carbondioxide which is increasing day by day must be reduced. This can only done if somewhere the carbon di oxide is absorbed this can be done by planting a tree from today onwards if every person start planting a single tree it can absorb 1 ton of carbon di oxide during 
its lifetime. Get a Report Card From Your Utility Company-There are many companies are in the market which are helping in providing free home audits which helps the consumers in identify wheather the place or area around is energy efficient or not. Likewise other companies are also available to make the place or area energy efficient Encourage Others To Conserve- One man can do nothing we need to encourage other peoples to do so. You just need to conduct the seminars and share the information among peoples about recycling, using less heat, replacement of bulbs with CFLs, and drive smart, buy energy efficient products, use less hot water, use the switch off, plant the tree etc. You can do these things to conserve our life and the upcoming life[62].

\section{REFERENCE}

[1] Anenberg, S. C., and others, 2009: Intercontinental impacts of ozone pollution on human mortality. Environmental Science \& Technology.

[2] [ Erickson, L.E., \& Jennings, M. (2017). Energy, transportation, air quality, climate change, health nexus: Sustainable energy is good for our health, AIMS Public Health, 4, 47-62. Issue].

[3] Munsell, M. (2017). US Solar Market Grows 95\% in 2016. Smashes Records, Boston, Massachusetts: Green Tech Media;

[4] (Zeger et al., 2000; Sheppard et al., 2005)

[5] [Mann, Michael E. (2014-04-01). "Earth Will Cross the Climate Danger Threshold by 2036". Scientific American. Retrieved 30 August 2016.]

[6] [Charlson, R.J.; S E Schwartz; J M Hales; R D Cess; J A Coakley; J E Hansen; D J Hofmann (1992). "Climate forcing by anthropogenic aerosols". Science. 255 (5043): 423-30. Bibcode:1992Sci...255..423C ].

[7] [ Andino, Jean M. (October 21, 1999). ॥CFCs are Heavier than Air, so how ,do scientists suppose that these Chemicals reach the Altitude of the Ozone Layer to adversly affect it . Scientific American. 264: 68].

[8] [Scientific Assessment of Ozone Depletion: 2010. World Meteorological Organization. 2011. Retrieved March 13, 2015]

[9] Molina, M.J.; Rowland, F.S. (1974), "Stratospheric sink for chlorofluoromethanes: chlorine atom-catalysed destruction of ozone" Nature, 249:810812, Bibcode:1974Natur.249..810M, doi:10.103 8/249810a0 ] 
[10] -Climate Change Resolution 39-1\| (To reduce emissions at least 35-45\% by 2030). New England Governors \& Eastern Canadian Premiers. 2015

[11] George, K.; Ziska, L.H.; Bunce, J.A.; Quebedeaux, B. (2007). "Elevated atmospheric CO 2 concentration and temperature across an urban-rural transect". Atmospheric Environment. 41 (35): 7654-7665].

[12] Climate Change: Impacts, Vulnerabilities and Adaptation in Developing Countries. Bonn. 2007. Accessed: 6th May 2009. http://unfccc.int/resource/docs/publications/impacts.pdf

[13] Ocean Acidification: A National Strategy to Meet the Challenges of a Changing Ocean. Washington, DC: National Academies Press. 2010- 04-22. doi:10.17226/12904]

[14] "EMEP/EEA air pollutant emission inventory guidebook - 2009". Eea.europa.eu. 200906-19. Retrieved 2012-12-11].

[15] Vehicles, Air Pollution, and Human Health." Union of Concerned Scientists, www.ucsusa.org/clean-vehicles/vehicles-air-pollution-and- human-health]

[16] Stocker, T. F.; Qin, D.; Plattner, G.-K.; Tignor, M.; Allen, S. K.; Boschung, J.; Nauels, A.; Xia, Y.; Bex, V.; Midgley, P. M. (2013). "The Physical Science Basis - Summary for Policymakers"(PDF). IPCC WGI AR5 (Report). p. 4].

[17] Le Treut; et al. "Chapter 1: Historical Overview of Climate Change Science". FAQ 1.1. Archived from the original on 23 December 2018. Retrieved 22 December 2018., p. 97].

[18] Russell, Randy (16 May 2007). "The Greenhouse Effect \& Greenhouse Gases". University Corporation for Atmospheric Research Windows to the Universe. Archived from the original on 28 March 2010. Retrieved 27 December 2009.].

[19] Cook, John (13 April 2016). "Consensus on consensus: a synthesis of consensus estimates on human-caused global warming". Environmental Research Letters. 11 (4): 048002. Bibcode:2016ERL. 11d8002C. doi:10.1088/1748-

9326/11/4/048002].

[20] Rovere, A., Stocchi, P., \& Vacchi, M. (2016). Eustatic and Relative Sea Level Changes. Current Climate Change Reports,2(4), 221-

231. doi:10.1007/s40641-016-0045-7].

[21] Lal, R. and B. A. Stewart. 1990... Soil degradation. Springer- Verlag, New York].

[22] Carrington, Damian (21 May 2018). "Humans just $0.01 \%$ of all life but have destroyed $83 \%$ of wild mammals - study". TheGuardian.com. Retrieved 23 May 2018] 
[23] Farman J., Gardiner B., Shanklin J. 1985. Large losses of total ozone in Antarctica reveal seasonal $\mathrm{ClOx} / \mathrm{NOx}$ interaction. Nature 315.

[24] "Stratospheric Ozone Depletion by Chlorofluorocarbons (Nobel Lecture)—Encyclopedia of Earth". Eoearth.org. Archived from the original on September 9, 2011].

[25] Mitchell, John F. B. (1989). "The "Greenhouse" effect and Climate Change" (PDF). Reviews of Geophysics. 27 (1): 115-139].

[26] Vaclav Smil (2003). The Earth's Biosphere: Evolution, Dynamics, and Change.

[27] [Gilgen, H., Wild, M., Ohmura, A., 1998. Means and trends of shortwave irradiance at the surface estimated from global energy balance archive data. J. Climate 11, 2042-2061].

[28] arxiv.org/abs/1209.0536: Probing Planck's Law for an Object Thinner than the Thermal Wavelength.

[29] Annex II Glossary". Intergovernmental Panel on Climate Change. Retrieved 15 October 2010 .

[30] MolIna M j \& Rowland F S. Stratospheric sink for chlorofluommethanes-chlonne atomic catalyscd destruction of ozone. Nature 249:810-2. 1974 (Cited 510 times.)

[31] Nemet G.F., Holloway T., Meier P. Implications of incorporating air-quality co-benefits into climate change policymaking. Environ. Res.

[32] Estimating the health effects of greenhouse gas mitigation strategies: addressing parametric, model, and valuation challenges.

[33] "Politicians sign new climate pact". BBC. 2007-02-16. Retrieved 2007-05-28

[34] Climate talks face international hurdles". Associated pressm the original on 2008-12-18. Retrieved 2007-08-03

[35] Nemet G.F., Holloway T., Meier P. Implications of incorporating air-quality co-benefits into climate change policymaking. Environ. Res.

Lett. 2010;5:14007

[36] Incropera, F.P. (2016). Climate Change: A Wicked Problem: Complexity and Uncertainty at the Intersection of Science, Economics, Politics, and Human Behaviour. New York, NY: Cambridge University Press.

[37] Feng, Y., Ramanathan, V., Investigation of aerosol-cloud interactions using a chemicaltransport model constrained by satellite observations, in preparation.

[38] Wéry N., Galès A., Brunet Y. (2017). Bioaerosol SOURCES in Microbiology of Aerosols, eds Delort A.M., Amato P., editors. (Hoboken, NJ: John Wiley \& Sons, Inc.), 115135 . 
[39] Van Leuken J., Swart A., Havelaar A., Van Pul A., Van der Hoek W., Heederik D. (2016). Atmospheric dispersion modelling of bioaerosols that are pathogenic to humans and livestock-a review to inform risk assessment studies

[40] Chung, C.E., Ramanathan, V., Kim, D., Podgorny, I.A., 2005. Global anthropogenicaerosol direct forcing derived from satellite and ground-based observations.

D24207. J. Geophys. Res. 110. doi:10.1029/2005JD006356.

[41] Alpert, P., Kishcha, P., 2008. Quantification of the effect of urbanization on solar dimming. L08801. Geophysics. Res. Lett. 35, doi: 10.1029/2007GL033012.

[42] Wild, M., Ohmura, A., Gilgen, H., Rosenfeld, D., 2004. On the consistency of trends in radiation and temperature records and implications for the global hydrological cycle. Geophysics. Res. Lett. 31 2003GL091188

Streets, D.G., Wu, Y., Chin, M., 2006. Two-decadal aerosol trends as a likely explanation of the global dimming/brightening transition. L15806.

Geophys. Res. Lett. 33. Doi: 10.1029/2006GL026471

[43] Ramanathan, V., Carmichael, G., 2008. Global and regional climate changes due to black carbon. Nat. Geosci. 1, 221-227.

[44] Gilgen, H., Wild, M., Ohmura, A., 1998. Means and trends of shortwave irradiance at the surface estimated from global energy balance archive data. J. Climate 11, 2042-2061

[45] Ramanathan, V., et al., 2001a. The Indian Ocean experiment: an integrated assessment of the climate forcing and effects of the great Indo-Asian Haze. J. Geophys. Res. 106 (D22), 28371-28399.

[46] Intergovernmental Panel on Climate Change (IPCC), 2007. Climate change 2007: the scientific basis. In: Solomon, S. (Ed.), Contribution of Working Group I to the Fourth Assessment Report of theIntergovernmental Panel on Climate Change. Cambridge Univ. Press, New York.

[47] Mitchell Jr., J.M., 1970. A preliminary evaluation of atmospheric pollution as a cause of the global temperature fluctuation of the past century. In: Fred Singer, S. (Ed.), Global Effects of Environmental Pollution. Springer-Verlag, New York, pp. 139-155.

[48] Hansen, J., Nazarenko, L., 2004. Soot climate forcing via snow and ice albedos. Proc. Natl. Acad. Sci., U.S.A. 101, 423-428

[49] Mitchell Jr., J.M., 1970. A preliminary evaluation of atmospheric pollution as a cause of the global temperature fluctuation of the past century. In: Fred Singer, S. (Ed.), Global Effects of Environmental Pollution. Springer-Verlag, New York, pp. 139-155. 
[50] Streets, D.G., Wu, Y., Chin, M., 2006. Two-decadal aerosol trends as a likely explanation of the global dimming/brightening transition. L15806. Geophysics'. Res. Lett. 33. Doi: 10.1029/2006GL026471.

[51] Lie pert, B.G., 2002. Observed reductions of surface solar radiation at sites in the United States and worldwide from 1961 to 1990. Geophysics'. Res. Lett. 29 (10), 1421. Doi: 10.1029/2002GL014910.

[52] Ohmura, A., Gilgen, H., Wild, M., 1989. Global energy balance archive GEBA, World Climate Pogrom - Water Project A7. Report 1: Introduction. Zurrcher GeogrqLdte Schripen, 34. Vedag der Fachvercine, Zurich. 62pp.

[53] Penner, J.E., Chuang, C.C., Grant, K., 1998. Climate forcing by carbonaceous and sulphate aerosols. Claim. Dyne. 14, 839-851.

Stanhill, G., Cohen, S., 2001. Global dimming: a review of the evidence for a widespread and significant reduction in global radiation with discussion of its probable causes and possible agricultural consequences. Agric. Forest Meteorol. 107, 255-278.

[54] Stanhill, G., Cohen, S., 2001. Global dimming: a review of the evidence for a widespread and significant reduction in global radiation with discussion of its probable causes and possible agricultural consequences. Agric. Forest Meteorol. 107, 255-278.

[55] Lie pert, B.G., 2002. Observed reductions of surface solar radiation at sites in the United States and worldwide from 1961 to 1990. Geophysics. Res. Lett. 29 (10), 1421. Doi:10.1029/2002GL014910.

[56] Wild, M., Ohmura, A., Gilgen, H., Rosenfeld, D., 2004. On the consistency of trends in radiation and temperature records and implications for the global hydrological cycle. Geophys. Res. Lett. 312003 GL091188.

[57] Stanhill, G., Cohen, S., 2001. Global dimming: a review of the evidence for a widespread and significant reduction in global radiation with discussion of its probable causes and possible agricultural consequences. Agric. Forest Meteorol. 107, 255-278.

[58] Wild, M., Gilgen, H., Roesch, A., Ohmura, A., Long, C., Dutton, E., Forgan, B., Kallis, A., Russak, V., Tsvetkov, A., 2005. From dimming to brightening: decadal changes in solar radiation at the Earth's surface. Science 308, 847-850.

[59] Ramanathan, V., Li, F., Ramana, M.V., Praveen, P.S., Kim, D., Corrigan, C.E., Nguyen, H., 2007b. Atmospheric brown clouds: hemispherical and regional variations in long range transport, absorption, and radiative forcing. D22S21. J. Geophys. Res. 112. doi:10.1029/2006JD008124

[60] IPCC. (2014). Climate Change 2014: Synthesis Report. Contribution of Working Groups I, II and III to the Fifth Assessment Report of the Intergovernmental Panel on Climate Change 
[Core Writing Team, R.K. Pachauri and L.A. Meyer (eds.)]. IPCC, Geneva,Switzerland, 151 pp.Retrieved January 23, 2017

[61] Vestreng, V., et al., 2007. EMEP (Co-operative Programme for Monitoring andEvaluation of the Long Range Transmission of Air Pollutants in Europe) expertemissions, Inventory Report 2007.

[62] Cohen S.j.,\&Waddell M.W (2009).Climate Change in the 21st Centuary.Montreal;McGILL-Queen`s University Press. 